\title{
FATORES CONDICIONANTES DOS MOVIMENTOS DE MASSA NO MUNICÍPIO DE AGUDO/RS
}

Angeli Aline Behling ${ }^{1}$ Andrea Valli Nummer ${ }^{2}$ Anderson Augusto Volpato Sccoti ${ }^{3}$

\begin{abstract}
Resumo: Os movimentos de massa são importantes processos geomorfológicos, responsáveis pelo modelado da superfície terrestre. 0 objetivo deste estudo foi identificar fatores condicionantes dos movimentos de massa no munícipio de Agudo. Para determinar os condicionantes, foram utilizadas informações cartográficas e trabalhos de campo. Onze processos foram identificados, os quais foram representados em mapas temáticos. $O$ resultado indica que os fatores mais significativos são: declividade, contatos entre diferentes tipos de rochas e contato do colúvio com o solo residual (neossolo) ou rocha sedimentar alterada. A metodologia utilizada mostrou-se eficaz, possibilitando qualificar as informações obtidas dos mapas temáticos, cujas escalas de informações eram regionais.
\end{abstract}

Palavras-chave: Escorregamentos. Colúvios. Declividade

\section{CONDITIONERS FACTORS OF MASS MOVEMENTS IN THE COUNTY OF AGUDO/RS}

\begin{abstract}
The mass movements are important geomorphological processes, responsible for the modeling of the earth's surface. The objective of this study was identified factors conditioners the mass movements in Agudo county. To determine the conditioners, were used cartographic information and field work. Were eleven processes identified, which were plotted on thematic maps. The result indicated that the most significant factors were: slope, contacts between different types of rocks and contact of the colluvium with residual soil (neosol) or altered sedimentary rock. The methodology used proved to be effective, enabling the qualification of the information obtained from the thematic maps, whose scales of information were regional.
\end{abstract}

Keywords: Landslides. Colluvium. Slope

\section{FACTORES DE CONDICIONANTES DE MOVIMIENTOS DE MASAS EN EL MUNICIPIO DE AGUDO / RS}

Resumen: Los movimientos de masa son procesos geomorfológicos importantes, responsables del modelado de la superficie terrestre. El objetivo de este trabajo fue identificar los factores condicionantes de los movimientos de masa en el municipio Agudo. Para determinar los condicionantes, se utilizaron informaciones cartográficas y trabajos de campo. Fueron identificados once procesos, los cuales fueron representados en varios mapas temáticos. Los

\footnotetext{
1 Prefeitura Municipal, São Gabriel, Brasil, gelibehling@gmail.com, https://orcid.org/0000-0002-62269692

2 Universidade Federal de Santa Maria, Departamento de Geociências, Santa Maria, Brasil, a.nummer@gmail.com, https://orcid.org/0000-0001-9271-442X

3 Universidade Federal de Santa Maria, Departamento de Geociências, Santa Maria, Brasil, asccoti2@gmail.com, https://orcid.org/0000-0001-8667-0432
} 
resultados indican que los factores más significativos son: la pendiente, los contactos entre diferentes tipos de rocas y contacto del coluvio con el suelo residual (neosolo) o roca sedimentaria alterada. La metodología utilizada se mostró eficaz, permitiendo la comparar las informaciones obtenidas de los mapas temáticos, cuyas escalas de información eran regionales.

Palabras clave: Movimientos de massa. Factores condicionantes. Deslizamientos.

\section{Introdução}

Os movimentos de massa são reconhecidos como os mais importantes processos geomorfológicos modeladores da superfície terrestre. Constituem-se no deslocamento de material (solo e rocha) vertente abaixo, sob influência da gravidade, desencadeado pela interferência direta de outros agentes independentes (BIGARELLA, 2003).

O município de Agudo, localizado no centro do estado do Rio Grande do Sul, apresentou a ocorrência de movimentos de massa ao longo dos últimos anos. Conforme a classificação apresentada pelo IBGE (2010), o município de Agudo ocupa três compartimentos geomorfológicos, sendo nas porções mais elevadas topograficamente o Planalto da Serra Geral; nas altitudes médias, o Rebordo do Planalto e nas porções mais baixas, a Depressão Periférica, com destaque para a depressão do Jacuí.

As formas predominantes de relevo no município, conforme Schirmer (2015), são ao norte (planalto da Serra Geral), áreas compostas por uma associação de colinas onduladas, morros e morrotes com vertentes de declividade acentuada; na porção central, o rebordo do planalto, representado por morros e escarpas e, na depressão do Jacuí, ao Sul e sudoeste, colinas suaves e áreas planas associadas à hidrografia.

A escolha da área de estudo deu-se em virtude dos registros de movimento de massa no município e pelo fato da temática ir ao encontro das atividades desenvolvidas pelo Laboratório de Geologia Ambiental (LAGEOLAM).

O objetivo geral desta pesquisa foi avaliar os fatores que condicionam os processos de movimentos de massa, com destaque para os escorregamentos, corridas de detrito e rastejo que ocorreram no Município de Agudo/RS. Como objetivos específicos: i) fazer um levantamento das cicatrizes dos movimentos de massa ocorridos no município, localizando-os espacialmente; ii) descrever e classificar os processos com base em fatores como: geologia- litologia, solo, 
hipsometria, declividade, forma de vertente e uso e ocupação; iii) identificar os fatores condicionantes dos movimentos de massa no município de Agudo e como eles comportam-se, possibilitando, assim, ações mitigatórias que promovam o correto planejamento dessas áreas.

O município de Agudo tem seus limites político-administrativos com Ibarama ao norte, Lagoa Bonita e Nova Palma a noroeste, Restinga Seca a sudoeste, Paraíso do Sul ao sul e Cerro Branco a leste (Figura 1).

Figura 1: Mapa de Localização de Agudo/RS.

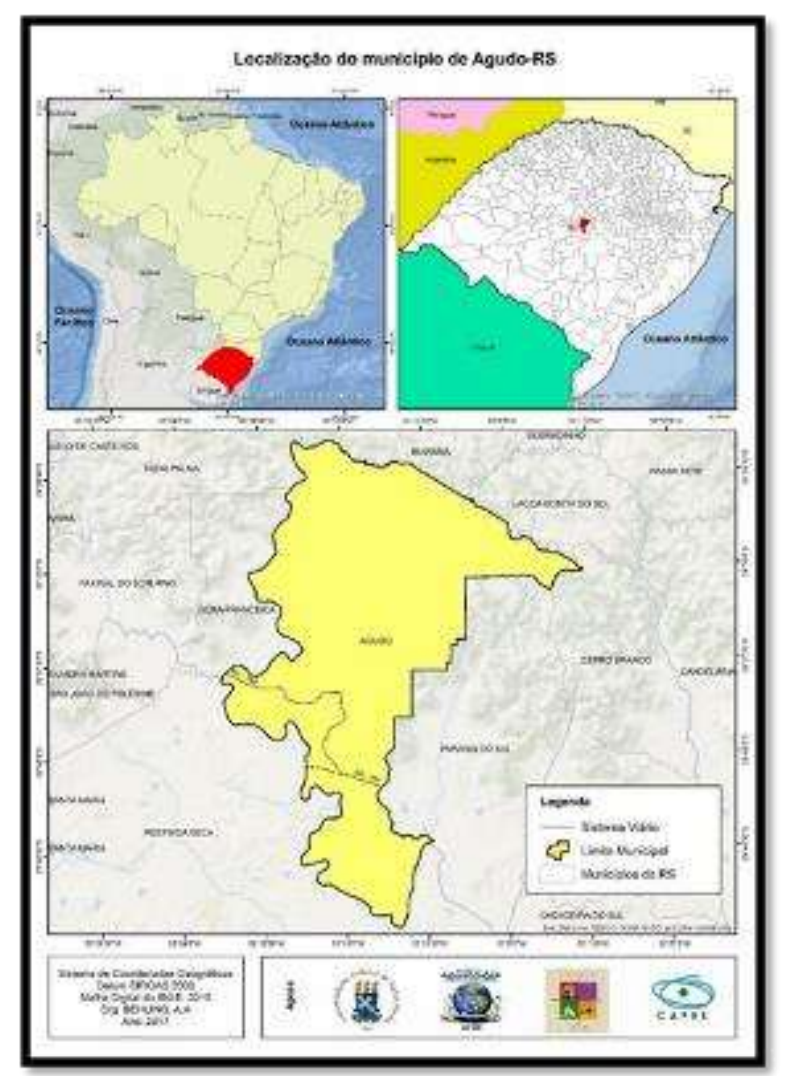

\section{PROCEDIMENTOS METODOLÓGICOS}

Para a elaboração deste trabalho, utilizou-se uma abordagem sistêmica, buscando, assim, discutir de maneira dialética a relação entre os componentes do ambiente e, com isso, definir quais são as características que podem definir a ocorrência ou não dos movimentos de massa com base em fatores condicionantes.

Para a identificação da ocorrência de movimentos de massa, foi realizada, em um primeiro momento, uma interpretação visual de imagens disponibilizadas pelo Google Earth $\AA$, onde foram identificadas as cicratizes, 
com solo exposto e associadas a encostas de morros e morrotes, o que poderia configurar escorregamentos, corrida de detritos, leques de deposição de corrida de detritos, etc. As informações coletadas remotamente foram validadas em campo.

Procurando qualificar o banco de dados e ampliar a quantidade de informações, buscou-se notícias sobre processos de movimentos de massa no jornal local "Correio Agudense", abarcando os anos de 2014 e 2015.

Para avaliação dos movimentos de massa no campo, foi utilizado o laudo de vistoria que consta na norma técnica ABNT-NBR 11682- Estabilidade de Encostas, com algumas modificações e adaptações para atender os objetivos deste estudo. Uma das modificações que foi implantada nessa norma foi a classificação dos movimentos em que foi utilizada a de Augusto Filho (1992).

Foram realizadas três visitas a campo, a primeira para identificação dos processos, no ano de 2015, e as demais para aplicar o laudo de vistoria e os registros fotográficos, sendo que a segunda, em outubro de 2016, e a última, em janeiro de 2017, para ter-se um intervalo de tempo e, assim, localizar um número maior de processos decorrentes dos últimos períodos chuvosos.

Nas identificações dos movimentos, foram coletadas informações tais como: localidade (coordenadas geográficas), tipo de evento, área de abrangência, danos causados. Já nas características técnicas, foram avaliados os materiais envolvidos (Solos e/ou rochas), forma da vertente, presença de água, profundidade da superfície de ruptura, uso do solo no entorno, influência antrópica como cortes, aterros, retirada da vegetação, tendo, como modelo, o laudo de vistoria que consta na ABNT-NBR 11682 (2009).

Para os trabalhos de campo, foram utilizados os seguintes materiais: um receptor de GPS modelo Garmim 62 SX - empregado para a coleta de pontos e posterior georreferenciamento dos movimentos de massa; câmera fotográfica, martelo e bússola. Quando não era possível aproximar-se do local da cicatriz, por questões de acesso, utilizou-se a bússola para orientar a direção da visada com relação ao ponto de aquisição do ponto de GPS. Isso orientou a posterior localização dos pontos na imagem do Google Earth.

Os movimentos de massa identificados foram representados nos diferentes mapas temáticos (fatores) elaborados em escala 1:50.000, processados com o auxílio do software ArcGIS® 10.1, procurando compreender a relação dos processos com cada um dos fatores. 
Foram elaborados mapas temáticos que correspondem aos fatores condicionantes dos processos de movimentos de massa:

-Geologia - Litologia: Tomou-se como base o Mapa Litológico do município de Agudo, de Schirmer (2012), na escala 1: 50.000.

-Solo: Para a geração do Mapa de Solos, foi utilizada a base georreferenciada organizada por Streck et al (2002) na escala 1:250.000.

-Relevo: Para avaliação dos fatores relativos ao relevo foram elaborados três mapas temáticos: hipsométrico; declividade, forma de perfil e plano de curvatura das vertentes.

-Hipsometria: A hipsometria do município foi definida a partir do Modelo Digital de Elevação (MDE), obtida pela imagem Shuttle Radar Topography Mission (SRTM) com resolução de 30 metros.

Para a inferência do Mapa Hipsométrico, foram definidas classes em intervalos de 100 metros, as quais possibilitam a individualização dos principais compartimentos topográficos do município. Para cada um dos processos foi extraído o valor absoluto da altimetria.

-Declividade: O mapa de declividade do município foi gerado a partir do Modelo Digital de Elevação (MDE). O mapa foi definido a partir do fatiamento da declividade em intervalos de valores em porcentagemas e seguindo a classificação estabelecida pelo IPT 1981 (Instituto de Pesquisas Tecnológicas de São Paulo).

-Forma de perfil e plano de curvatura das vertentes: Para a geração do mapa das formas das vertentes, utilizou-se a imagem SRTM com resolução de 30 metros. Essa informação foi integrada no SIG para auxiliar na definição dos condicionantes a movimento de massa.

-Uso e Ocupação da Terra: A classificação da imagem (mês de novembro de 2015), para a elaboração do mapa de uso e ocupação da Terra, deu-se através do software ENVI 5.1 e na edição dos mapas finais, utilizou-se o

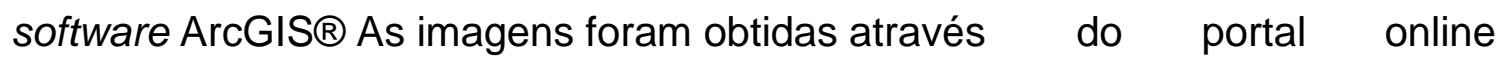
(http://earthexplorer.usgs.govf) da USGS.

Por fim, as informações foram integradas e, através da avaliação dos produtos cartográficos e informações de campo, ocorreu a indicação dos principais fatores condicionantes dos movimentos de massa. 


\section{RESULTADOS E DISCUSSÕES}

Os movimentos de massa no município ocorreram em encostas onde não há interferência antrópica, ou seja, encostas com vegetação arbórea endêmica e nos cortes de estradas, atingindo, de forma indireta, a população. No jornal local, foram encontradas três reportagens, dos anos de 2014 e 2015, que abordam, de forma superficial, eventos de movimentos de massa no município. Comumente nas reportagens que o jornal do município repassou para a pesquisa, foi possível observar que, somente em um caso, há o destaque para os movimentos de massa, pois ele obstruiu uma via e impossibilitou o tráfego de pessoas e veículos. Foram identificados 11 processos de movimentos de massa por meio de suas cicatrizes. A Tabela 1 mostra as coordenadas de cada ponto e o tipo de processo identificado.

Tabela 1: Descrição e localização espacial dos eventos relacionados a movimentos de massa.

\begin{tabular}{c|c|c}
\hline Pontos & Descrição & Coordenadas UTM \\
\hline 1 & Queda & $281394-6734418$ \\
\hline 2 & Escorregamento em Cunha & $281335-6734385$ \\
\hline 3 & Escorregamento Rotacional/Rastejo & $276383-6730427$ \\
\hline 4 & Escorregamento Planar & $279589-6729347$ \\
\hline 5 & Escorregamento Planar & $280363-6727139$ \\
\hline 6 & Escorregamento Planar/Corrida de Detrito & $282631-6726416$ \\
\hline 7 & Escorregamento Planar & $277109-6719651$ \\
\hline 8 & Escorregamento Planar & $277303-6719473$ \\
\hline 10 & Escorregamento Planar/ Corrida de Detrito & $281634-6719034$ \\
\hline 11 & &
\end{tabular}


Figura 2: Carta Imagem com localização dos movimentos de massa no município de Agudo.

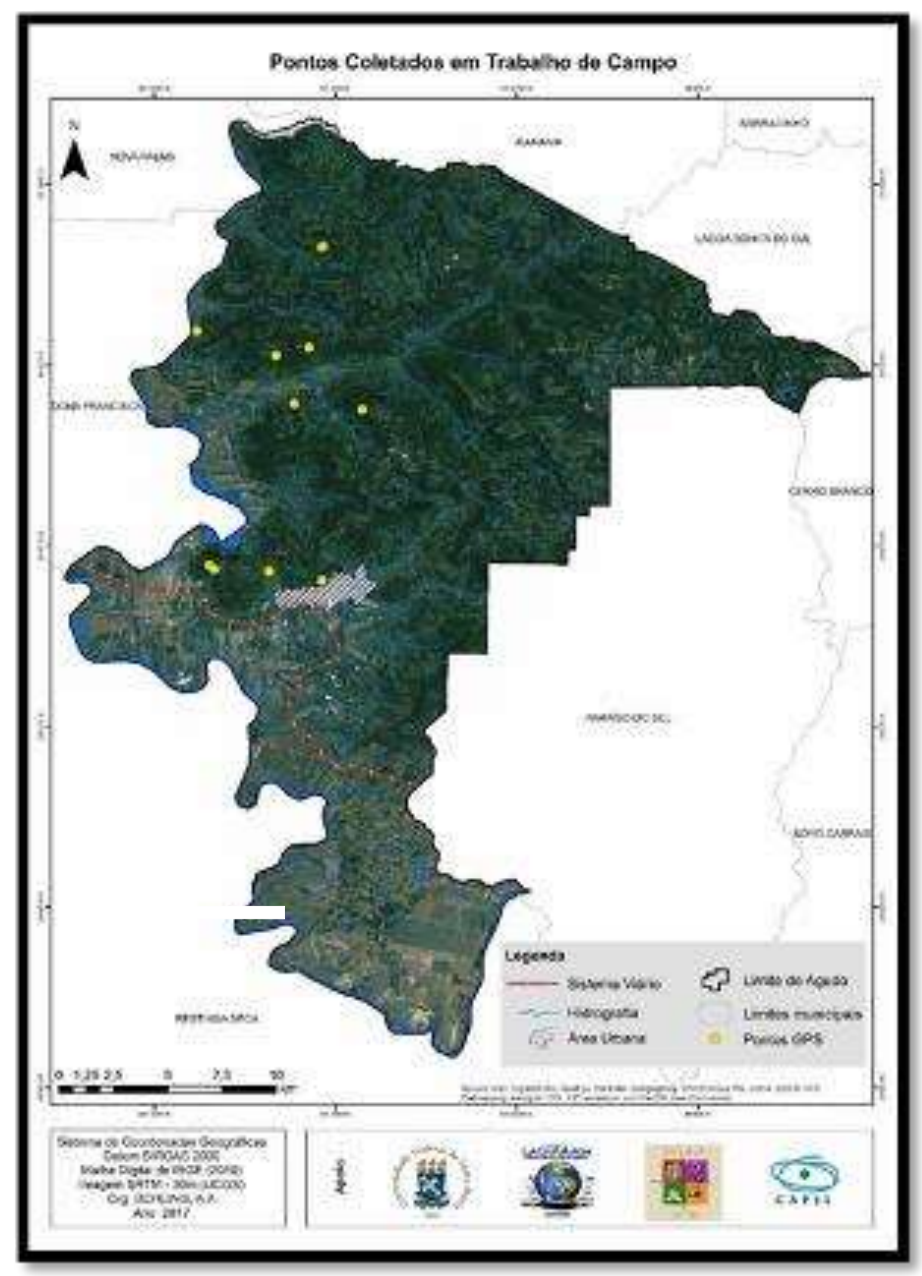

$\mathrm{Na}$ sequência, foi elaborado um mosaico de fotografias, onde foram agrupados os movimentos de massa:

1ํ. Queda, Escorregamento em Cunha: Os movimentos de queda e ruptura em cunha (Figura 4) ocorreram em talude de corte de estrada em rocha vulcânica coberta por solo residual e tálus, onde os processos de movimentos de massa são controlados pela presença das disjunções horizontais e verticais (quedas) e por falhas tectônicas (em cunha). Nesse mesmo talude, também ocorrem escorregamentos planares associados às falhas e disjunções. Nesses dois processos, há um forte componente antrópico, que é o corte executado para a construção da estrada, pois ele desestabiliza as forças de equilíbrio do talude, facilitando a sua ruptura. 
Figura 3: Mosaico: Movimentos de Massa - tipo: Queda e Escorregamento em Cunha - Pontos 1 e 2.

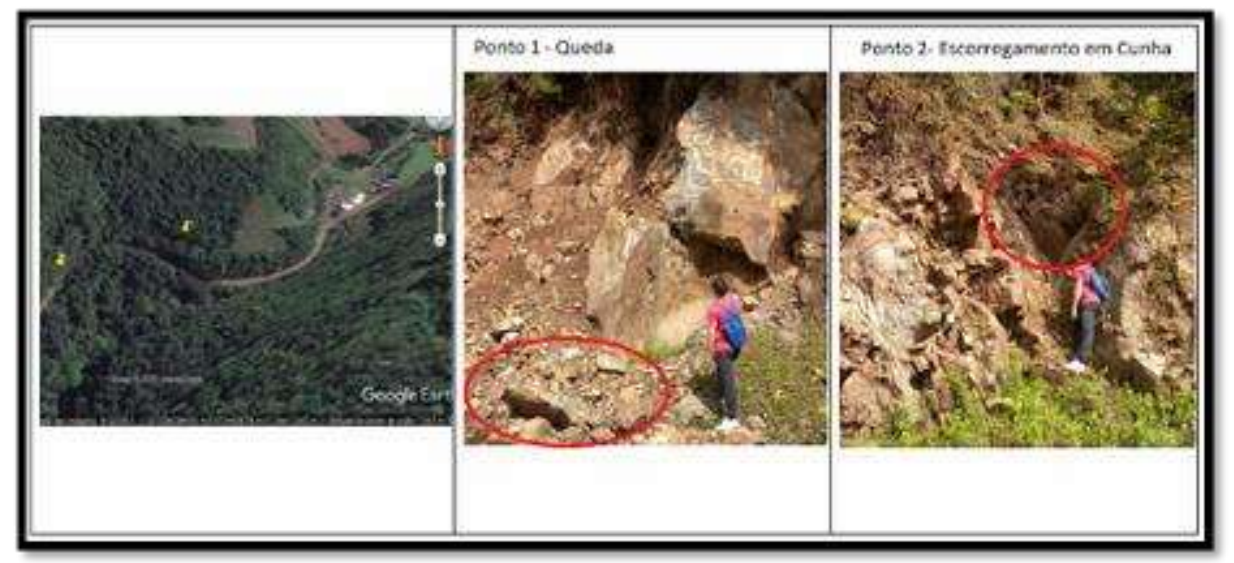

Fonte: Google Earth

A vegetação na área desses movimentos de massa é predominantemente arbórea de porte de média a alta. O relevo é do tipo escarpado com perfil côncavo, e plano de curvatura divergente. As superfícies de ruptura ocorrem no contato rocha- rocha (escorregamento em cunha, escorregamento planar e queda). Em alguns locais as quedas podem estar associadas à presença de rocha alterada.

$2^{0}$ - Escorregamento Rotacional; Rastejo: Os escorregamentos rotacionais (Figura 5) ocorrem de forma localizada e estão relacionados diretamente aos taludes de corte de estradas ou dos cursos de água. O corte na base do talude (estrada) ou a erosão (rio) cria uma instabilidade na encosta.

As áreas onde foram identificados os escorregamentos apresentam vegetação composta por gramíneas (nessas áreas, a vegetação arbórea foi substituída), a drenagem é natural em condições satisfatórias, isto é, ela flui, não permanecendo no sistema. O relevo é ondulado a escarpado e a forma da vertente é côncavo-divergente. Durante a vistoria de campo, o solo estava em uma condição de saturação com surgência de água no contato do colúvio com o solo residual.

Os escorregamentos rotacionais têm a sua superfície de cisalhamento no contato do colúvio e solo residual com a rocha alterada. Os rastejos ocorrem em material coluvionar sobre solos residuais, abrangendo uma área significativa. São identificados pela presença de blocos de rocha ou linhas de pedras e trincas no terreno. A superfície de ruptura dá-se no contato do colúvio com o solo residual, ou localmente no colúvio sobre rocha alterada (Figura 5). 
Figura 4: Mosaico: Movimentos de Massa - tipo: Escorregamento Rotacional e Rastejo - Pontos 3 e 10 .

Fonte: Google Earth

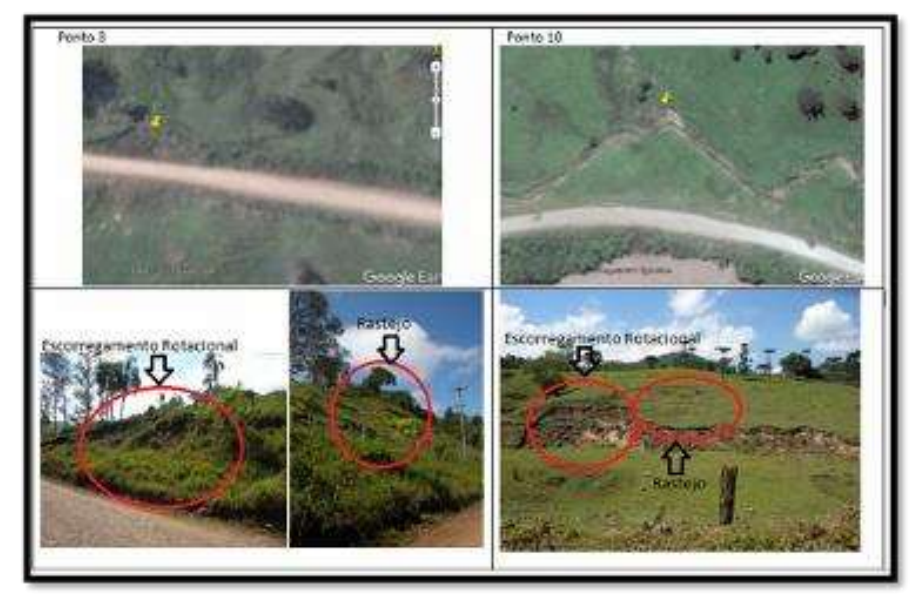

3ำ - Escorregamento Planar: São processos rápidos que deixam cicatrizes retilíneas de solos expostos. Foram identificados em maior quantidade e estão localizados em áreas de declividades acentuadas, tendo o seu início no topo das encostas (Figura 6). São processos rasos associados à presença de colúvios/tálus sobre rochas alteradas de origem sedimentar (arenitos).

A vegetação é predominantemente arbórea de porte médio a alta. A drenagem natural em condições satisfatória (água fluindo do sistema), o relevo é escarpado em vertentes côncavo-divergentes (ponto 5), côncavo-convergente (ponto 6), convexos-convergente (ponto 8 e 9). As superfícies de ruptura de todos os escorregamentos dão-se no contato do colúvio com a rocha alterada, também percebe-se que os processos têm início no contato nas rochas vulcânicas com as sedimentares, o que pode ser associado à maior disponibilidade de água nessas áreas.

Figura 5: Mosaico: Movimento de Massa - tipo: Escorregamento Planar - Pontos 5, 6, 8 e 9.

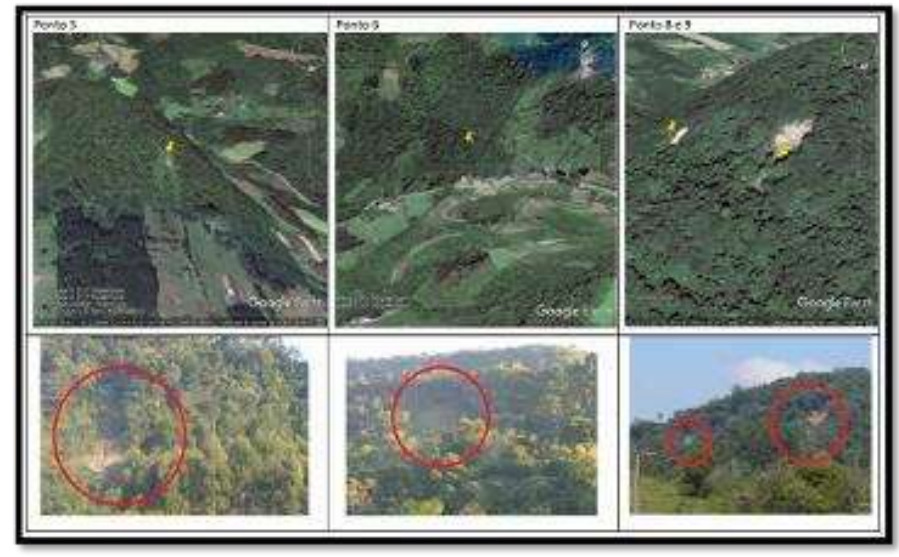


Fonte: Google Earth

$3^{\circ}$ - Corrida de Detrito e Escorregamento Planar: Os processos classificados como corridas de detritos estão associados a escorregamentos planares, isto é, iniciam como escorregamentos e, depois, encontram um curso de água de primeira ordem, onde se encaixam e por meio dos quais os detritos descem pela encosta. São processos rápidos, restritos aos cursos de água onde mobilizam um certo volume de material que, nessa região, não são muito significativos. Depositam uma variedade de materiais em sua área de dissipação como: blocos de rocha (vulcânicas), finos como areias, siltes e argilas, galhos de árvores etc.

Iniciam em áreas bastante declivosas e de grande altitude, o que justifica o difícil acesso a esses locais, sendo possível somente avaliar o material já depositado (Figura 7).

A drenagem é natural, o relevo é escarpado, a sua vertente é côncavoconvergente (onde ocorrem as corridas de detritos). O início do processo dá-se pelo aparecimento de um escorregamento planar numa vertente convexodivergente que está ligada lateralmente a uma vertente côncavo-convergente, onde passa a ocorrer as corridas de detrito.

Figura 6: Mosaico: Movimentos de Massa - tipo: Escorregamento Planar e Corrida de Detrito Pontos 4,7 e 11.

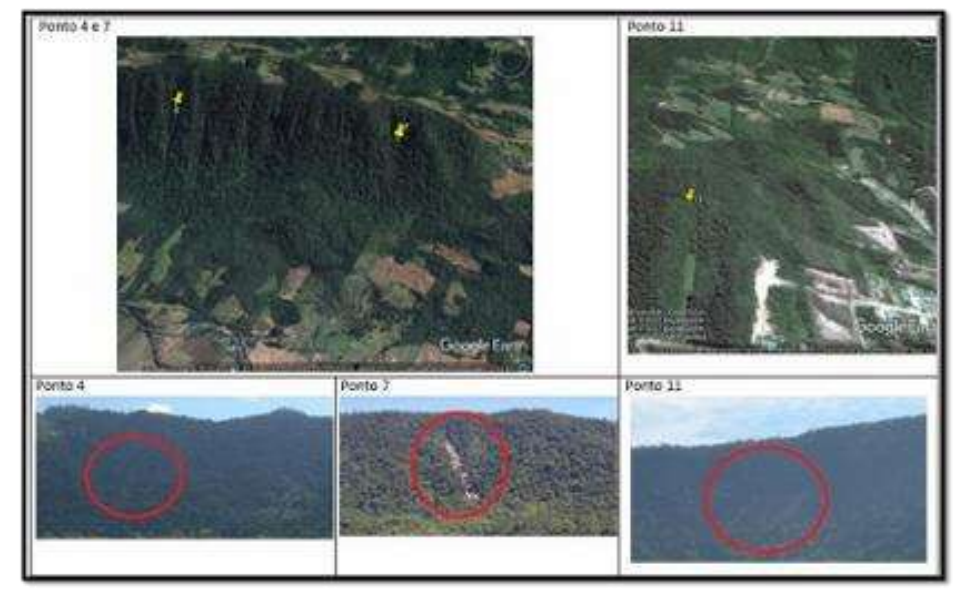

Fonte: Google Earth

Os processos identificados em campo e descritos utilizando-se o laudo de vistoria foram locados nos diferentes mapas temáticos que representam os fatores que condicionam os movimentos de massa, procurando identificar de que forma eles contribuem para que os eventos ocorram. 


\section{Fatores Condicionantes aos movimentos de Massa}

Geologia - Litologia - as litologias encontradas na área de estudo, compõem parte da Bacia Sedimentar do Paraná, são elas: Grupos Rosário do Sul (Formações Santa Maria e Caturrita) e São Bento (Formações Botucatu e Serra Geral).

A maior parte das ocorrências de movimentos de massa está associada a locais onde se encontram a Formação Serra Geral e Caturrita, localizados em taludes de cortes de estradas e encostas naturais.

$\mathrm{Na}$ Tabela 2 encontram-se os movimentos de massa observados em campo e seus respectivos aspectos litológicos. Devido à escala do mapa, nem todos os pontos corresponderam às litologias identificadas em campo, principalmente os escorregamentos planares e corridas de detritos (pontos 4, 6 e 7), que têm início no contato das rochas vulcânicas com as sedimentares.

Tabela 2: Formação Litológica dos movimentos de massa, assinalados os resultados que há correspondência entre os dados de campo e laudo.

\begin{tabular}{c|c|c|c}
\hline Pontos & Processos & Formações Mapas & $\begin{array}{c}\text { Formações } \\
\text { Laudos }\end{array}$ \\
\hline 1 & Queda & Vulcânica & Vulcânica \\
\hline 2 & Escorregamento em Cunha & Vulcânica & Vulcânica \\
\hline 3 & Escorregamento Rotacional/Rastejo & Arenito fluvial fino e maciço & Sedimentar \\
\hline 4 & Escorregamento Planar/Corrida de Detrito & Vulcânica & Sedimentar \\
\hline 5 & Escorregamento Planar & Arenito fluvial fino e maciço & Sedimentar \\
\hline 6 & Escorregamento Planar & Vulcânica & Sedimentar \\
\hline 7 & Escorregamento Planar/Corrida de Detrito & Vulcânica & Sedimentar \\
\hline 8 & Escorregamento Planar & Arenito fluvial fino e maciço & Sedimentar \\
\hline 9 & Escorregamento Planar & Arenito fluvial fino e maciço & Sedimentar \\
\hline 10 & Escorregamento Rotacional/Rastejo & Arenito fluvial fino e maciço & Sedimentar \\
\hline 11 & Escorregamento Planar/Corrida de Detrito & Arenito fluvial fino e maciço & Sedimentar \\
\hline
\end{tabular}

Os colúvios são compostos por blocos de rocha ígneas e até mesmo sedimentares, com matriz areno-siltosa a argilosa, pouco espessa (principalmente em áreas de declividade acentuada) e, na maioria das vezes, encontra-se sobre um solo residual raso (escorregamentos planares e corridas de detritos) ou até mesmo sobre solos residuais mais espessos e rocha 
sedimentar alterada (escorregamentos circulares).

A diferença de permeabilidade do colúvio (que é maior) para o solo residual e/ou rocha alterada (menor) possibilita que a água escoe no contato desses materiais, originando uma superfície de ruptura devido à queda da resistência ao cisalhamento pela poropressão. Esse fato vai ao encontro ao trabalho de Silveira (2010), que destaca que a infiltração da água no interior do talude causa aumentos significativos de poropressão, diminuindo a resistência ao cisalhamento dos materiais.

Solo - Os solos que ocorrem no município de Agudo são do tipo: Nitossolos, Argissolos brunos, Argissolos vermelhos, Neossolos e Planossolos .

Os processos de movimentos de massa ocorreram em dois tipos principais de solo: nos Neossolos (escorregamentos planares e corridas de detritos) e nos Argissolos (escorregamentos rotacionais).

Os escorregamentos $\mathrm{e}$ as corridas de detritos que ocorreram nas encostas, em declividades acentuadas, estão relacionados ao contato do colúvio com o solo residual raso (Neossolos). Da mesma forma, os escorregamentos rotacionais, que são comuns em solos mais espessos, ocorreram nos Argissolos. Na Tabela 3 encontram-se os tipos de os solos e os processos identificados no município.

Tabela 3: Associação entre os tipos de movimentos de massa e os tipos de solos.

\begin{tabular}{c|c|c}
\hline Pontos & Processo & Solos \\
\hline 1 & Escorregamento em Cunha & Neossolo Litólicos Chernossólicos \\
\hline 2 & Escorregamento Rotacional/Rastejo & Argissolos Bruno-Acinzentado Alitico \\
\hline 3 & Escorregamento Planar/Corrida de Detrito & Neossolo Litólicos Chernossólicos \\
\hline 4 & Escorregamento Planar & Neossolo Litólicos Chernossólicos \\
\hline 5 & Escorregamento Planar/ Corrida de Detrito & Neossolo Litólicos Chernossólicos \\
\hline 6 & Escorregamento Planar & Neossolo Litólicos Chernossólicos \\
\hline 8 & Escorregamento Planar & Neossolo Litólicos Chernossólicos \\
\hline 9 & Escorregamento Rotacional/ Rastejo & Argissolos Bruno-Acinzentado Alitico \\
\hline 10 & Escorregamento Planar/ Corrida de Detrito & Neossolo Litólicos Chernossólicos \\
\hline
\end{tabular}

Hipsometria - As informações hipsométricas estabelecem uma visualização dos dados altimétricos do município, essencial para a sistematização dos diferentes compartimentos topográficos. 
A hipsometria do município é marcada pela presença de altitudes menores de 100 a maiores de 600 metros. As altitudes inferiores a 100 metros marcam as áreas planas junto à planície de inundação do Rio Jacuí, que se localiza longitudinalmente em toda parte oeste do município (desde do noroeste a sudoeste), bem como em áreas próximas aos arroios.

As altitudes situadas entre 100 a 200 metros correspondem a áreas onduladas, localizadas na porção central do município. Já as altitudes de 300 a 400 metros localizam-se na parte norte, associadas às áreas de morros e morrotes. As altitudes de 500 a 600 metros encontram-se na parte norte, local de transição da Depressão Central com o Planalto Meridional Brasileiro.

Declividade - As declividades situadas entre 5 a $15 \%$ destacam-se na porção central do município, não se identificaram movimentos de massa nessa faixa de declividade. Nas faixas de 15 a $30 \%$ que se distribuem longitudinalmente de norte ao sul, e no oeste do município, constataram-se movimentos associados a cortes de estradas. Na Tabela 5, encontram-se 0 processo, a faixa de declividade e a declividade exata do ponto.

Tabela 4: Declividade dos pontos coletados do município de Agudo - RS.

\begin{tabular}{c|c|c|c}
\hline Pontos & Processo & Declividade Mapa & $\begin{array}{c}\text { Declividade } \\
\text { Exata }\end{array}$ \\
\hline 1 & Queda & $>45 \%$ & $58,35 \%$ \\
\hline 2 & Escorregamento em Cunha & $>45 \%$ & $47,70 \%$ \\
\hline 3 & Escorregamento Rotacional/Rastejo & $15-30 \%$ & $29,46 \%$ \\
\hline 4 & Escorregamento Planar/Corrida de Detrito & $>45 \%$ & $86,67 \%$ \\
\hline 5 & Escorregamento planar & $>45 \%$ & $65,50 \%$ \\
\hline 6 & Escorregamento Planar & $>45 \%$ & $68,19 \%$ \\
\hline 7 & Escorregamento Planar/ Corrida de Detrito & $>45$ & $39,13 \%$ \\
\hline 8 & Escorregamento Rotacional/ Rastejo & $15-30 \%$ & $26,90 \%$ \\
\hline 9 & Escorregamento Planar/ Corrida de Detrito & $30-45 \%$ & $42,21 \%$ \\
\hline 10 & & $15-30 \%$ & \\
\hline 11 & & & \\
\hline
\end{tabular}

Forma da Vertente - Foram comparadas as classificações das vertentes no mapa com o laudo de campo e houve algumas disparidades, principalmente em relação ao plano de curvatura das vertentes. 
Os escorregamentos planares e corridas de detritos ocorrem em vertentes, cujo perfil é predominantemente côncavo e plano de curvatura convergente o que vai ao encontro com o trabalho desenvolvido por Scooti et al (2016), onde os autores destacam que os planos de curvatura convergentes proporcionam a concentração e o acúmulo de água, o que pode facilitar a ruptura.

Já os escorregamentos rotacionais ocorrem em vertentes de perfil côncavo e plano de curvatura convergente, perfeitamente justificável pelo acúmulo de água na base da vertente. Nesses processos, houve uma diferença na classificação do plano de curvatura da vertente no mapa (divergente) e no campo (convergente). Isso pode ser explicado pela escala do mapa que avalia a vertente de forma mais abrangente, diferente do campo que avalia a vertente no local da ruptura, onde o seu plano já se encontra modificado pelo processo. A Tabela 6 mostra a classificação das vertentes no mapa e no campo

Tabela 5: Forma da vertente dos pontos coletados no município de Agudo - RS

\begin{tabular}{|c|c|c|c|}
\hline Ponto & Processo & Curvaturas - Mapa & Curvatura - Laudo \\
\hline 01 & Queda & Côncavo - Divergente & Côncavo - Divergente \\
\hline 02 & Escorregamento em Cunha & Convexo - Divergente & Convexo - Divergente \\
\hline 03 & Escorregamento Rotacional/Rastejo & Côncavo - Divergente & $\begin{array}{l}\text { Côncavo - } \\
\text { Convergente }\end{array}$ \\
\hline 04 & $\begin{array}{c}\text { Escorregamento Planar/Corrida de } \\
\text { Detrito }\end{array}$ & $\begin{array}{l}\text { Convexo - } \\
\text { Convergente }\end{array}$ & $\begin{array}{l}\text { Côncavo - } \\
\text { Convergente }\end{array}$ \\
\hline 05 & Escorregamento Planar & Côncavo - Divergente & Côncavo - Divergente \\
\hline 06 & Escorregamento Planar & $\begin{array}{l}\text { Côncavo - } \\
\text { Convergente }\end{array}$ & $\begin{array}{l}\text { Côncavo - } \\
\text { Convergente }\end{array}$ \\
\hline 07 & $\begin{array}{c}\text { Escorregamento Planar/Corrida de } \\
\text { Detrito }\end{array}$ & Convexo - Divergente & $\begin{array}{l}\text { Côncavo - } \\
\text { Convergente }\end{array}$ \\
\hline 08 & Escorregamento Planar & Convexo - Divergente & Convexo- Convergente \\
\hline 09 & Escorregamento Planar & Côncavo - Divergente & Côncavo - Divergente \\
\hline 10 & Escorregamento Rotacional/Rastejo & Côncavo - Divergente & $\begin{array}{l}\text { Côncavo - } \\
\text { Convergente }\end{array}$ \\
\hline 11 & $\begin{array}{l}\text { Escorregamento Planar/Corrida de } \\
\text { Detrito }\end{array}$ & Convexo - Divergente & $\begin{array}{l}\text { Convexo - } \\
\text { Convergente }\end{array}$ \\
\hline
\end{tabular}


Uso e ocupação da Terra - Grande parte da população do município reside na área rural, onde a maioria dos processos de movimentos de massa foram identificada. As áreas íngremes, muitas vezes, são utilizadas para a produção de alimentos o qual serve para subsistência e/ou para a venda, sendo que, nesses locais, ocorrem a retirada da vegetação arbórea, para 0 desenvolvimento da agricultura.

\section{Definição dos fatores condicionantes dos movimentos de massa no município de Agudo - RS}

Foram analisados os fatores geológicos, solos, geomorfológicos, padrões morfétricos e de uso e ocupação da terra para que se pudesse definir quais contribuem para ocorrência de processos de movimentos de massa.

Os fatores que condicionam os movimentos estão relacionados, primeiramente, à declividade (entre $26 \%$ e $89 \%$ ), à presença de material coluvionar recobrindo a encosta (sobre neossolo raso ou rocha sedimentar alterada) e à forma de perfil e plano de curvatura das vertentes predominantemente côncavoconvergente ou côncavo-divergente, o que demonstra que há uma concentração do fluxo de água que facilita o surgimento dos processos.

A hipsometria não pode ser considerada como condicionante de movimentos de massa, porém baliza a cota, a partir da qual os processos começam a ocorrer (cicatrizes), o que na área de estudo, seria acima de $151 \mathrm{~m}$, essa altitude correspondendo à base do Rebordo do Planalto e ao início da encosta com declividades acentuadas.

\section{Considerações Finais}

De forma resumida, é possível elencar os fatores que são condicionantes dos processos avaliados: declividade, presença de colúvios, descontinuidades referentes a contato entre rochas de comportamentos diferentes (vulcânicas e sedimentares), forma da vertente que interfere na concentração de água, que é o fator que deflagra os movimentos.

Pode-se concluir que a presença da vegetação natural não inibe as ocorrências dos movimentos de massa, visto que esses processos são naturais e essenciais para evolução dos modelados que compõem o rebordo do planalto. 
Considera-se de extrema necessidade que essas áreas sigam preservadas, sem ocupação antrópica com lavouras ou moradias, uma vez que o contrário disso poderia desencadear perdas socioeconômicas significativas. Avalia-se que este trabalho pode ser utilizado como base para estudos referentes ao planejamento e ao uso adequado do espaço geográfico.

\section{REFERÊNCIAS}

ASSOCIAÇÃO BRASILEIRA DE NORMAS TÉCNICAS. NBR 11682:

Estabilidade de Encosta. Rio de Janeiro, 2009.

AUGUSTO FILHO, Oswaldo. Caracterização Geológica-Geotécnica Voltada à Estabilização de Encosta: uma Proposta Metodológica. In: 1aㅡ COBRAE, Rio de Janeiro, 1992. Anais... ABMS/ABGE, v.2, p. 721-733

BIGARELLA, João José. Estrutura e Origem das Paisagens Topicais e

Subtropicais. Vol 3. Florianópolis. Editora da UFSC, 2003.

INSTITUTO BRASILEIRO DE GEOGRAFIA E ESTATÍSTICA. Censo de 2010. Disponível em: $\leq$ http://www.censo2010.ibge.gov.br/>. Acesso em: 15 de jan. de 2015.

INSTITUTO DE PESQUISAS TECNOLÓGICAS. Mapeamento

Geomorfológico do Estado de São Paulo. São Paulo. Escala 1:500.000, v. 2, 1981

SCCOTI, Anderson Augusto Volpato; ROBAINA, Luis Eduardo de Souza; TRENTIN, Romario. Estudo do relevo da bacia hidrográfica do rio lbicuí com base em parâmetros morfométricos - oeste do Rio Grande do Sul. Geo UERJ, n. 29, p. 1-19, 2016.

SHIRMER, Gerson Jonas. Mapeamento Geoambiental dos Munícipios de Agudo, Dona Francisca, Faxinal do Soturno, Nova Palma e Pinhal Grande - RS. 2012. Dissertação (Mestrado em geografia). Universidade Federal de Santa Maria, Santa Maria, 2012.

SILVEIRA, Claudinei Taborda. Análise do relevo na Predição de Unidades Preliminares de Mapeamento de Solo: integração de Atributos Topográficos de Sistemas de Informações Geográficas e redes Neurais Artificias. 2010. Tese (Doutorado em Geografia). Universidade Federal do Paraná, Curitiba, 2010.

STRECK. Edemar Valdir; KAMPF, Nestor; DALMOLIN, Ricardo Simão Diniz; KLAMT, Egon; NASCIMENTO, Paulo César do; SCHNEIDER, Paulo. Solos do Rio Grande do Sul. Porto Alegre: Editora da UFRGS. Porto Alegre, 2002. 


\section{NOTAS DE AUTOR}

\section{CONTRIBUIÇÃO DE AUTORIA}

Angeli Aline Behling - Concepção. Coleta de dados, Análise de dados, Elaboração do manuscrito, revisão e aprovação da versão final do trabalho Andrea Valli Nummer - Concepção e elaboração do manuscrito. Coleta de dados Participação ativa da discussão dos resultados; Revisão e aprovação da versão final do trabalho.

Anderson Augusto Volpato Sccoti - Concepção e elaboração do manuscrito. Revisão e aprovação da versão final do trabalho.

FINANCIAMENTO

Não se aplica.

CONSENTIMENTO DE USO DE IMAGEM

Não se aplica.

APROVAÇÃO DE COMITÊ DE ÉTICA EM PESQUISA

Não se aplica.

\section{CONFLITO DE INTERESSES}

Não se aplica.

\section{LICENÇA DE USO}

Este artigo está licenciado sob a Licença Creative Commons CC-BY. Com essa licença você pode compartilhar, adaptar, criar para qualquer fim, desde que atribua a autoria da obra.

\section{HISTÓRICO}

Recebido em: 03-07-2019

Aprovado em: 15-02-2020 